\title{
EXPERIMENTAL STUDY OF TWO-PHASE THERMOSYPHON USING R-22 AS A WORKING FLUID
}

\author{
Maathe. A. Theeb ${ }^{1 *}$ \\ ${ }^{1}$ Department of Mechanical Engineering, Al-Musansiriyah University, Baghdad, Iraq.
}

\begin{abstract}
The two-phase closed thermosyphon (TPCT) is an effective heat transfer device decreasing the ground temperature around it in cold season. In this paper an experimental study has been done by using R-22 as a working fluids, the temperature and the pressure of the TPCT where measured with time (Transient study).
\end{abstract}

\section{Introduction}

Thermosyphon are enclose, passive two- phase heat transfer devices. They make use of the high efficient thermal transport process of evaporation and condensation to maximize the thermal conductance between a heat source and a heat sink. They are often referred to as thermal superconductors or thermal" short circuits" because they can transfer large amount of heat over relatively large distances with small temperature differences between the heat input and heat output zones. The amount of heat that can be transported by these devices is normally several orders of magnitude greater than pure conduction through a solid metal $[1,2]$.They are proven to be very affective, low cost and reliable heat transfer devices for applications in many thermal management and heat recovery systems. They are used in many applications including but not limited to passive ground/road anti freezing, baking ovens, heat exchangers in waste heat recovery applications, water heaters and solar energy systems and are showing some promise in high-performance electrons thermal management for situations which are orientation specific.[3] studied Heat transfer and hydrodynamics of two phase closed thermosyphon (TPCT), The mathematical model is formed for both vapor phase and liquid film in a non-dimensional form. The momentum and energy equations as parabolic equations have been solved by means of the locally one-dimensional scheme of A.A. Samarskii. The Poisson equation for the stream function has been approximated on the basis of the discrete scheme "cross". The obtained system of algebraic equations has been solved by the successive over relaxation method. The effect of the Rayleigh number on the velocity and temperature fields in the domain of interest and on the average Nusselt number at the solid-fluid interfaces is investigated. It was found that increase in the Rayleigh number leads to the increment of both the average Nusselt number and the stream function in the vapor zone.

* Corresponding author: bulba@tpu.ru 
A cross section of a closed two-phase thermosyphon is illustrated in fig (1).The thermosyphon consist of an evacuated sealed tube that consists a small amount of liquid. The heat applied at evaporator section is conducted across the pipe wall causing the liquid in thermosyphon to boil in the liquid pool region and evaporate and/or boil in the film region [4]. In this way the working fluid absorbs the applied heat load converting it to latent heat. The vapor in the evaporator zone is at a higher pressure than in the condenser section causing the vapor to flow upward. In the cooler condenser region the vapor condenses thus releasing the latent heat that was absorbed in the evaporation section. The heat then conducts across the thin liquid film and exits the thermosyphon through the tube wall and into the external environment. Within the tube, the flow circuit is completed by the liquid being forced by gravity back to the evaporator section in the form of thin a thin liquid film. As a thermosyphon relies on gravity to pump the liquid back to the evaporator section, it cannot operate at inclination close to horizontal position.

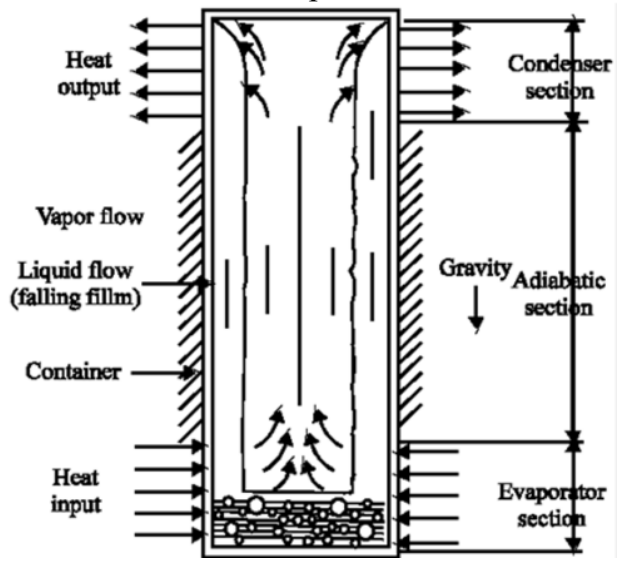

Fig. 1. Two-phase closed thermosiphon.

The studied thermosyphon consists of three classical sections including; an evaporator, an adiabatic section and a condenser. This thermosyphon has a length of $1 \mathrm{~m}$ with an internal and external diameter of $28.575 \mathrm{~mm}$ and $30.575 \mathrm{~mm}$, respectively. The length of the evaporation, adiabatic and condensation sections were design to be 30,30 and $30 \mathrm{~cm}$, respectively. In addition, a $10 \mathrm{~cm}$ space was left above the tube to collect any noncondensable gas.

The fluids tested were R-22 and R-134a, so we can make a comparison between each other. We should considered that the experiment was made in winter season.

The evaporator section was heated using an electrical heater. The heat input to the evaporator was adjusted using an electrical energy regulator with a maximum heat input of $1.5 \mathrm{~kW}$. We use the clamp meter to choose the proper heat value by choosing the proper current based on the assumption of the constant voltage.

$\mathrm{Q}=\mathrm{VI} \quad ; \mathrm{V}=220$ volt

Hence: $\mathrm{Q} \alpha \mathrm{I}$

For steady state cases The regulator was connected to thermostat in order to stabilize the temperature in the lower tank $(50,60,70,80)$ degree centigrade respectively in other words we stabilized the amount of the addition heat . The lower tank was mostly filled by water which transports heat by convection to the evaporator(absorbing latent heat)as shown in figure).It was closed by a plate and insulated by Glass wool in order to reduce the heat losses. The adiabatic zone was insulated by arm flex to minimize heat losses to the ambient. The condenser section of the thermosyphon was cooled by a flow of water, Condenser water was supplied via a constant-head water tank $30 \mathrm{~cm}$, This consisted of a tank and 
control valves as in figure, The temperature of the cold-water inlet was kept constant by those valves, the tank was uncovered and insulated by glass wool insulation, and the water temperature was about (20) degree centigrade. The temperature distribution along the thermosyphon was measured using four thermometers distributed respectively at lower water jacket (T1),adiabatic section (T2), condenser section (T3) and upper water jacket (T4)as shown in figure(3-1), the thermometers at adiabatic and condenser sections putted to be as much as possible directly contact within the pipe. The pressure along the thermosyphon was measured using a pressure gauge.

\section{MEASURING SYSTEM}

The measuring system includes the measurements of two parameters:

1. Temperature measurements system. Thermocouple probes of type-K with $(1.4 \mathrm{~m})$ long and $(3.18 \mathrm{~mm})$ in diameter were fixed at each point of the test the test rig, the calibration cureve shown in fig(2-c).

2. Refrigerant Pressure gages

low pressure gauges was fixed to measure the pressure inside the thermosyphone as shown in fig(2). This gauges is calibrated, the calibration shown in fig(2-d)

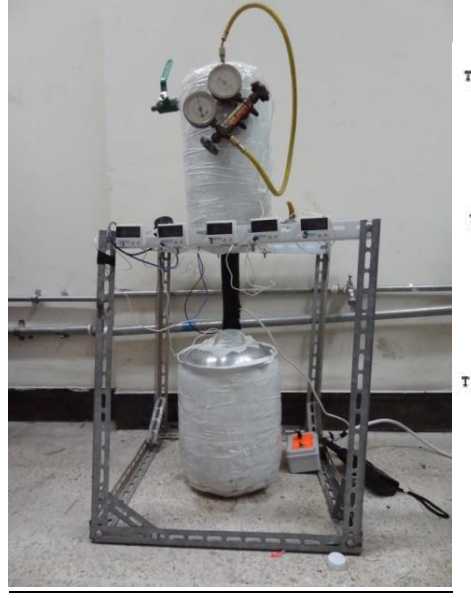

a

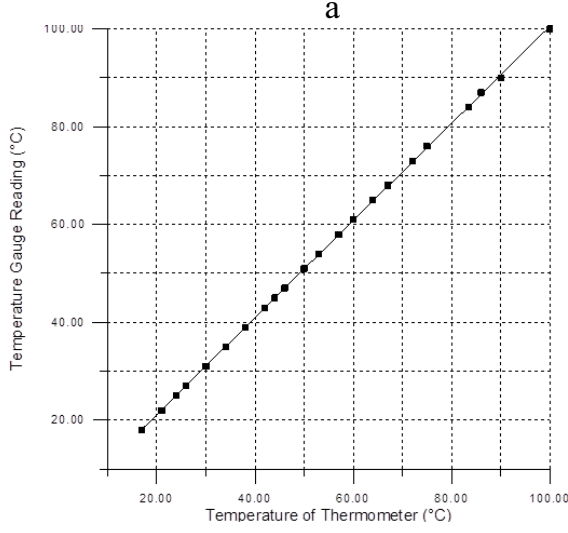

c

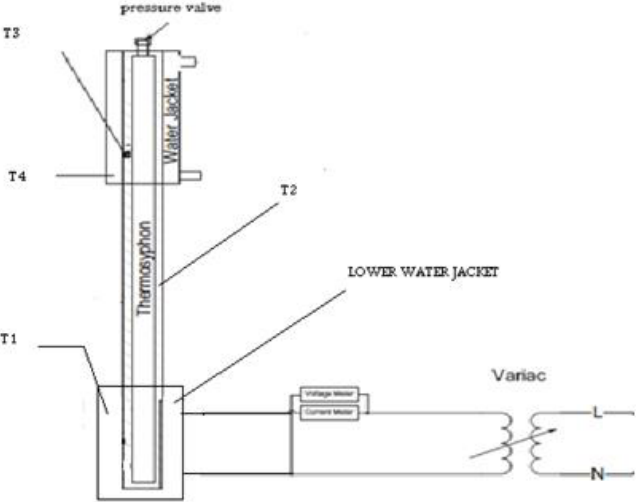

b

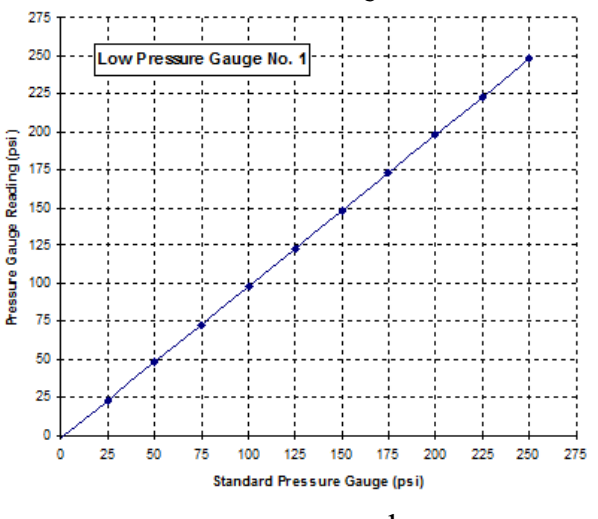

d

Fig. 2. (a,b)schematic diagram of thermosyphon test rig, (c) Calibration of temperature thermocouple type $\mathrm{K}$, (d) Calibration of the low pressure gauge. 


\section{Results and discussion}

At first we should know in what experimental circumstances the test was worked, the test is made in winter season at air temp 17 degree centigrade and that lead to increase the time for reaching the steady state .and the water which was used both in the test (the water jacket's) and in the calibration of thermometers was not distilled water so it effect at the result of this test the other problem was in electricity, the voltage was not constant. The thermosyphon pipe was compressed with R-22 \&R-134a gasses at $0.225 \mathrm{~g}$.

From the plots and tables below we can make a conclusion that the temperatures increased by time increasing and it's varied from temperature to another, we find the temperature of lower water jacket had large changes in temperature by time and this is true because is directly subjected to the heat source which is the heater in this test. The temperature of lower water jacket was increasing rapidly with reasonable changing in pressure, and the pressure is increasing by time increasing.

We can see in those tests that by current increasing the temperature increased better in other word the needed time for heating the same amount of water was less by current increases as we can see from tables that for the first 30 minutes the temperature

of the upper water jacket when current equal five AMPER is more than the other ones for the same current but different currents. We can find that by increasing the heat addition ( $q$ heater) the time needed for reaching the steady state case was less as we see it takes only 80 minutes otherwise it tokes 170 and 200 minutes for less heat subjected as it shown in R 22 tables as an example.

The R-22 is better in transporting heat than R-134a but the last one takes more time than the first one to reach the study state condition. For steady state condition we can make a conclusion which is how long time expends there is no changing in temperature of all sections and this means the heat amount is constant.

Fig (3) shows the temperature for different positions on the thermosyphon for the case of 2 Amp. Power supplies the evaporation zone (440 Watt). It shows that the at $180 \mathrm{~min}$ the TPCT will reach to the steady state conditions, while fig(4) shows the pressure gradient inside the TPCT with time, here we can conclude that the pressure will increase so we must be sure that the heat is rejected in the upper zone(condensation zone), fig(5) shows the effect of time with constant heat flux on the pressure of the TPCT, we can see that the pressure increasing with time while reaching the steady state.

Fig. $(6,7,8)$ show the effect of time on the temperature, pressureinside thermosyphon, time on pressure respectively for power supplies $3.5 \mathrm{Amp}$.(constant heat flux equal to 770 Watt.and $(9,10)$ for 1100 Watt. Fig. 2 shows the results of an experimental study of the heat transfer process in the steam thermal siphon tube channel (operating fluid - water): 


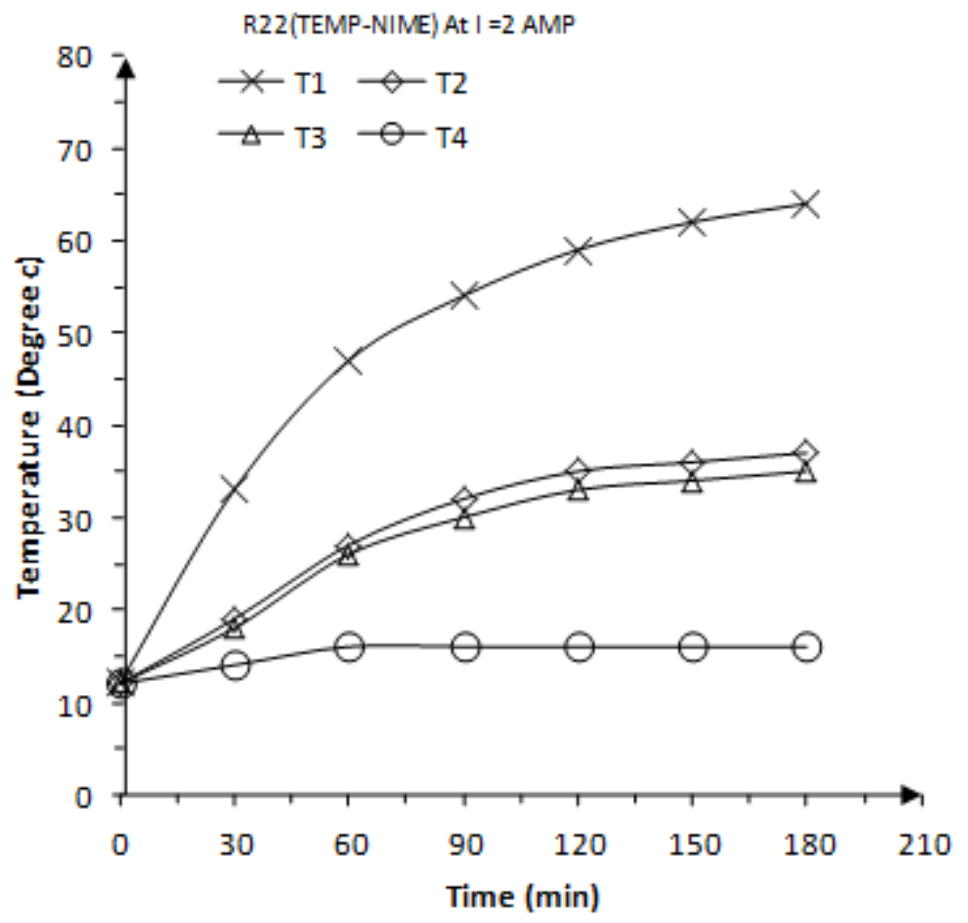

Fig. 3. Effect of time on the temperature.

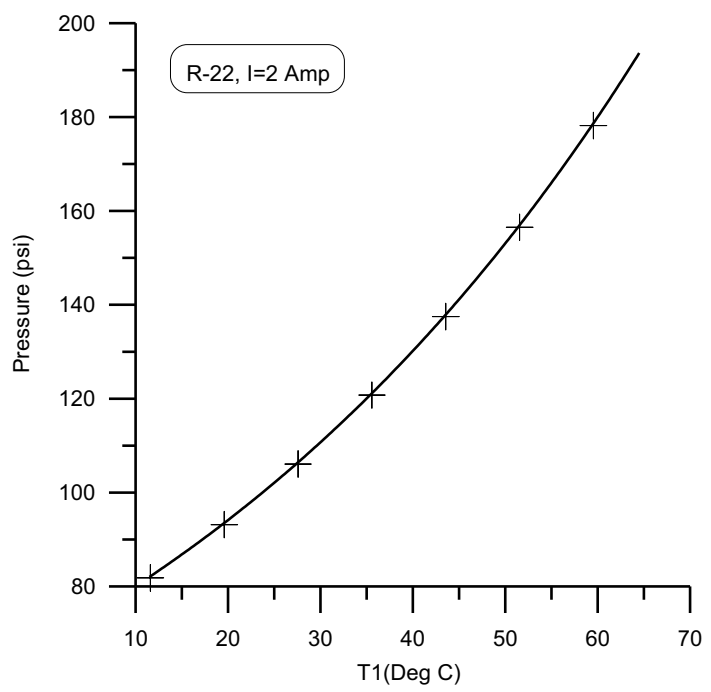

Fig. 4. Effect of temperature on the pressure. 


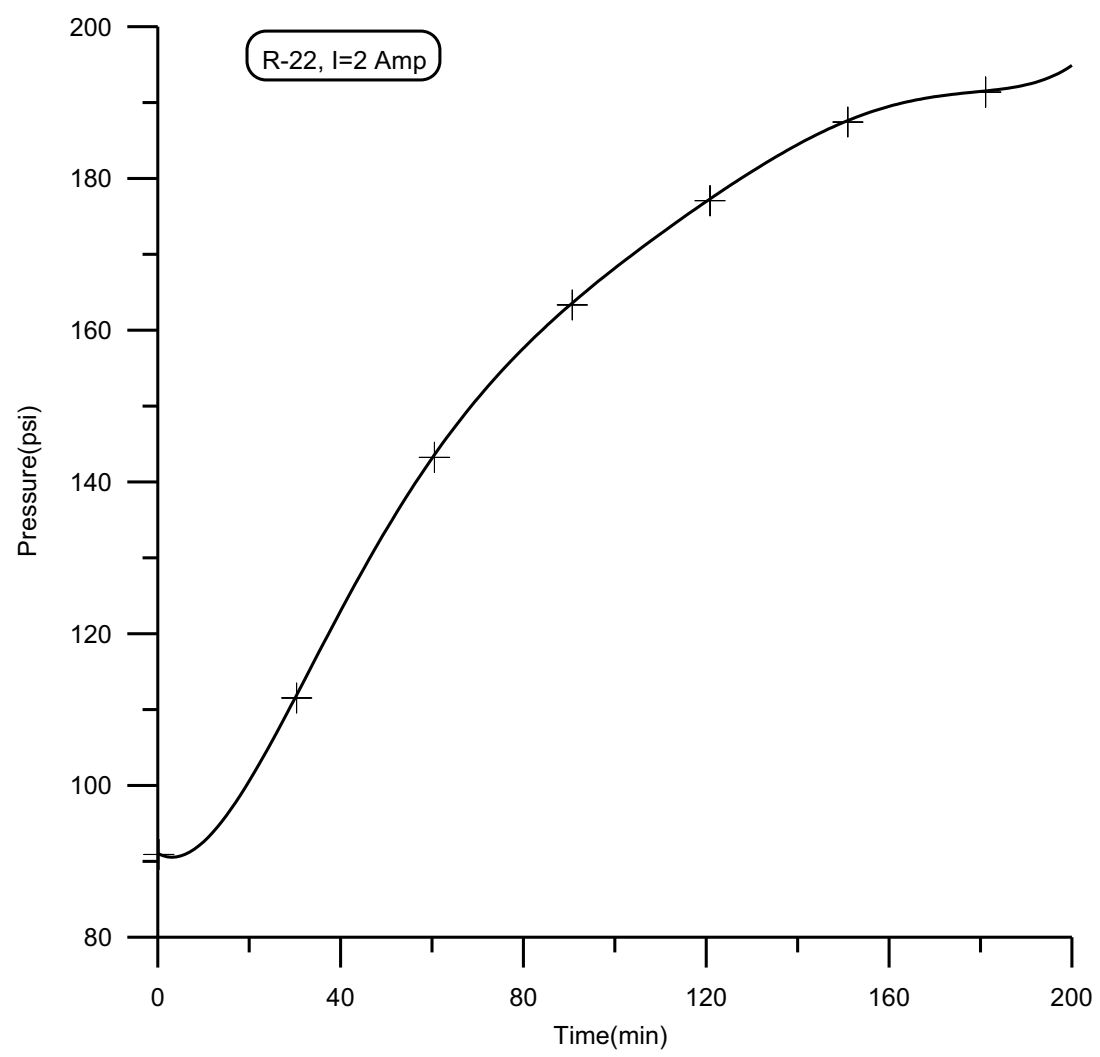

Fig. 5. Effect of time on the pressure.

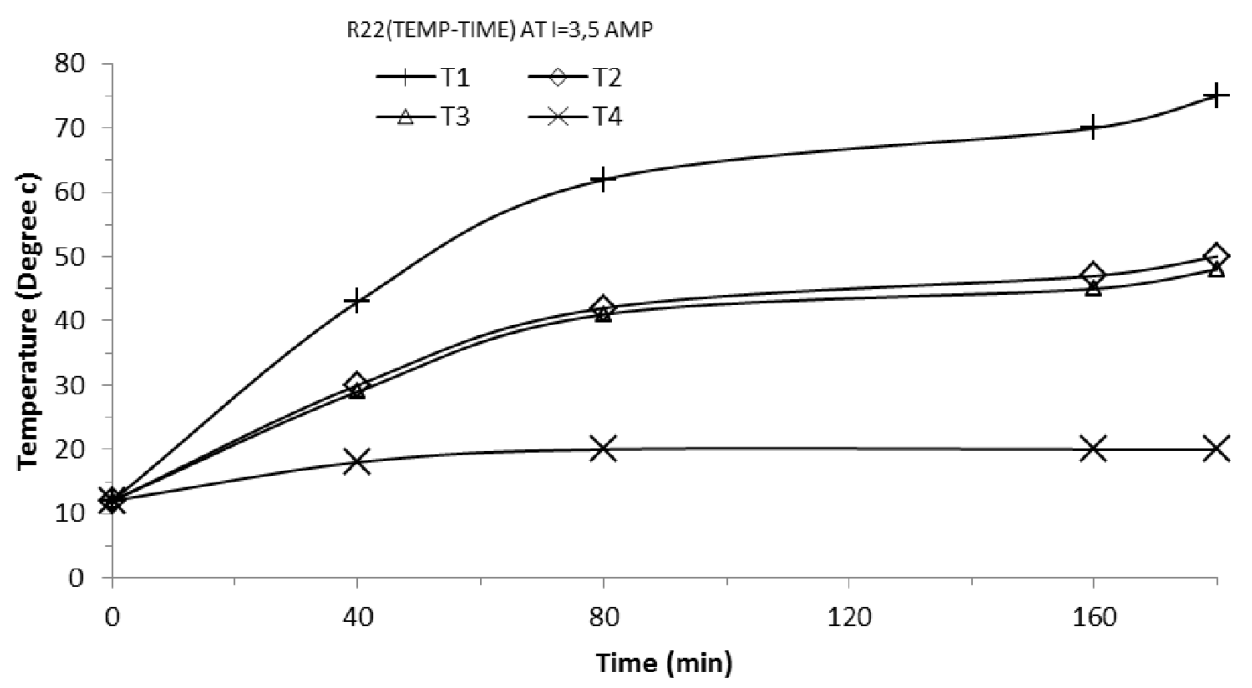

Fig. 6. Effect of time on the temperature. 


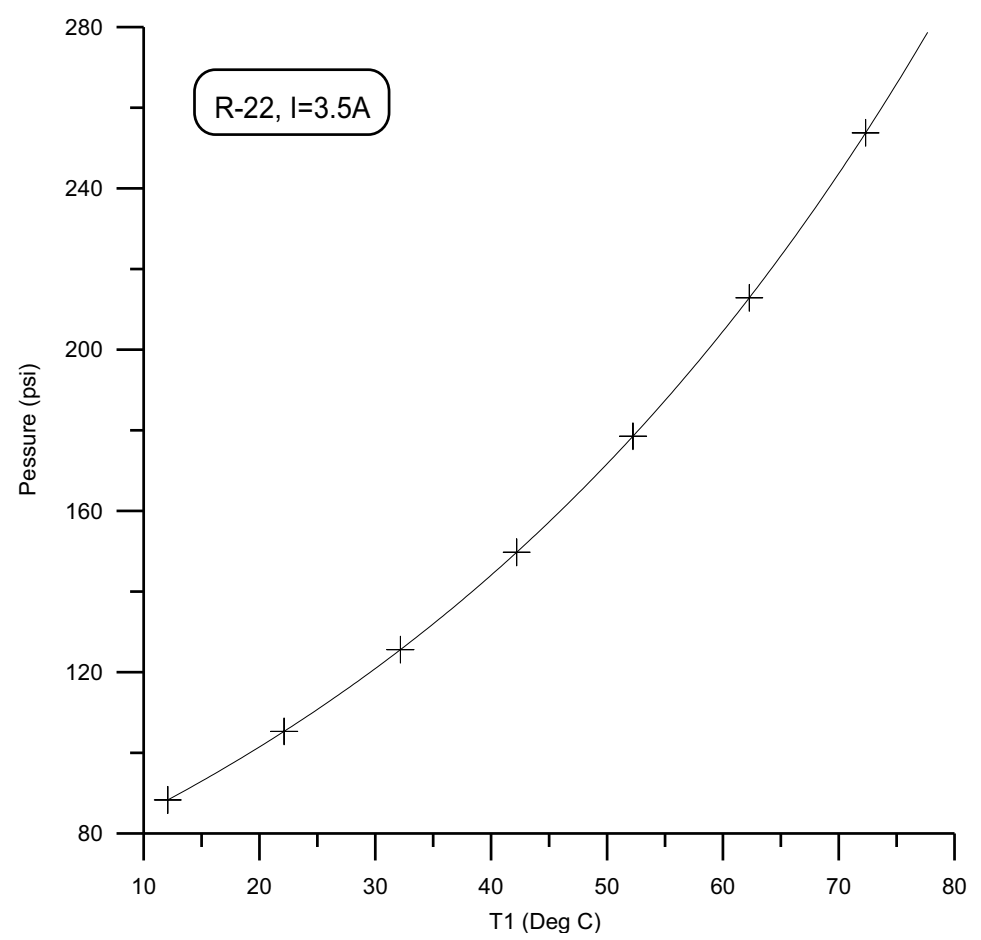

Fig. 7. Effect of temperature on the pressure.

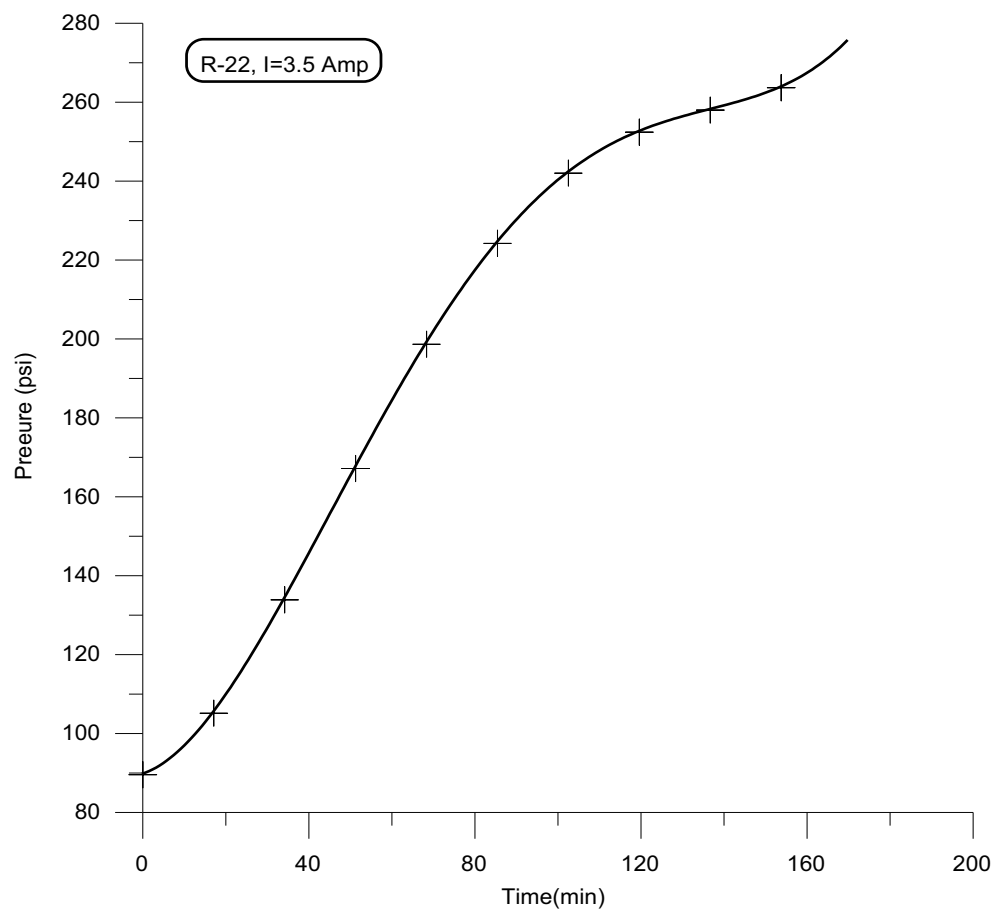

Fig. 8. Effect of time on the pressure. 


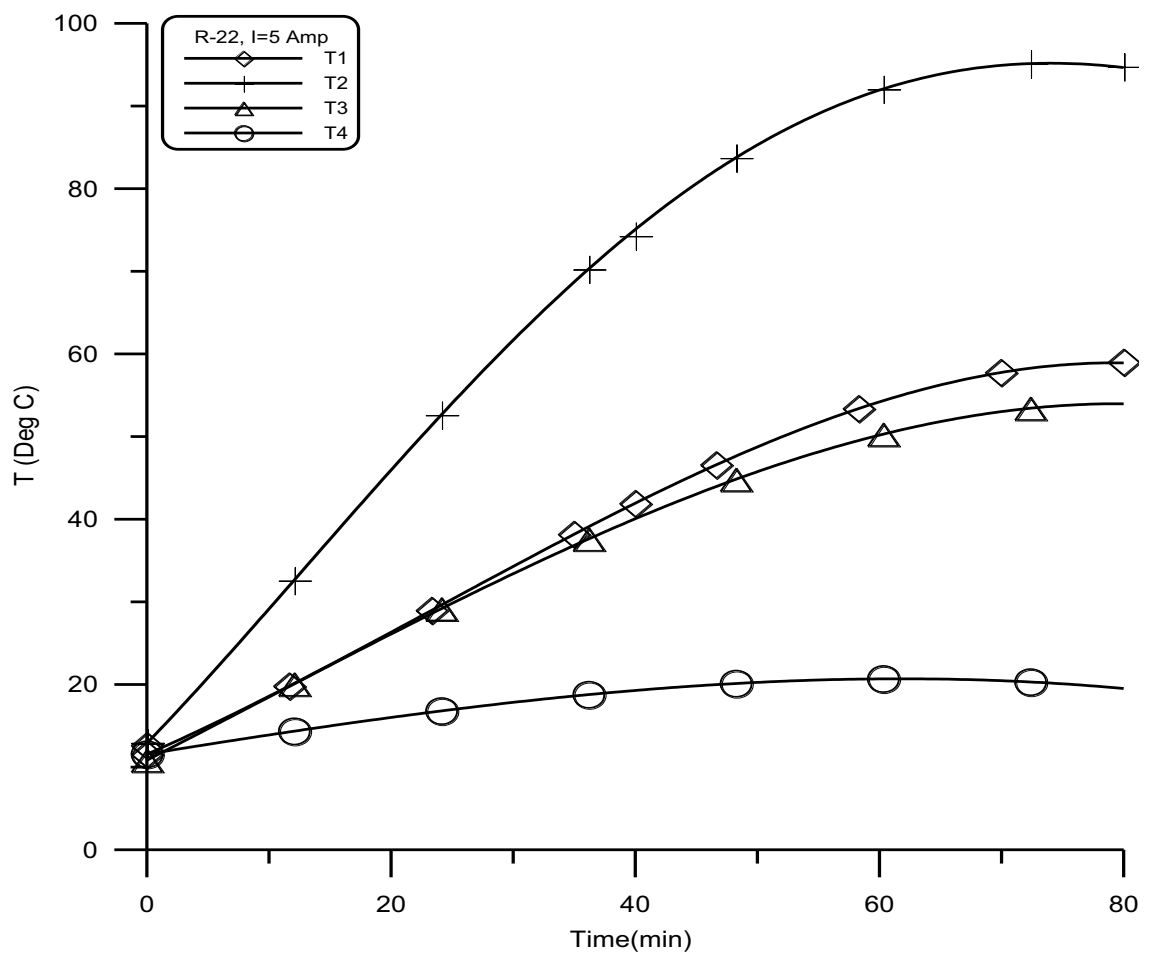

Fig. 9. Effect of time on the temperature.

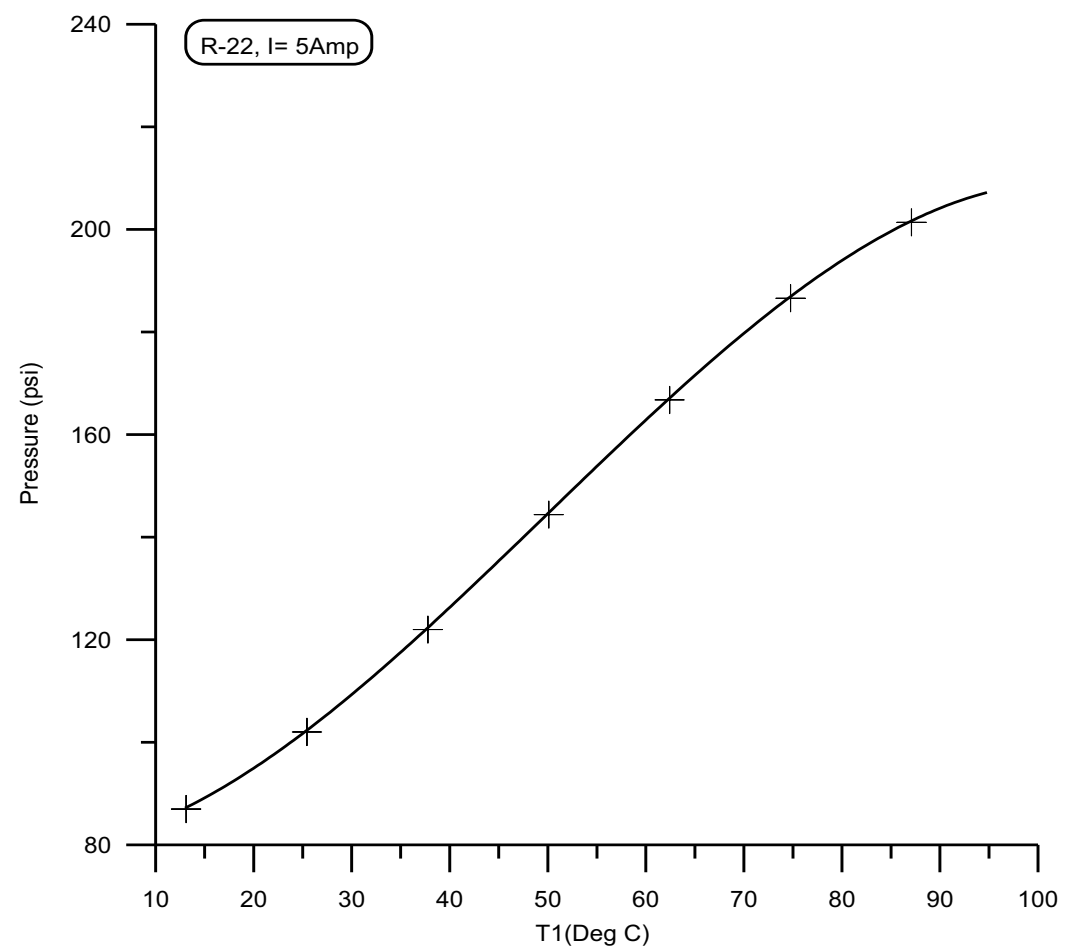

Fig. 10. Effect of temperature on the pressure. 


\section{Conclusion}

A small diameter thermosyphon was tested experimentally with two different working fluids: R-22 and R-134a. We find that:

1-The R-22 is better in transporting heat than R-134a but the last one takes more time than the first one to reach the study state condition.

2-Pressure inside TPCT increase with increasing the supply temperature so it is better to use a high efficiency heat transfer method to avoid increasing the pressure.

3-TPCT pressure increasing with time while reaching the steady state.

4-Increasing the heat flux will increase bothe the temperature and pressure for the TPCT.

\section{References}

1. S.H. Noie, Appl. Therm. Eng. 25 (2005)

2. D.A. Reay, P.A. Kew, Heat Pipes (Butterworth -Heinemann, Oxford, 2006)

3. G.V. Kuznetsov, M.A. Al-Ani and M.A. Sheremet, J. of En. and Pow. Eng. 5 (2011)

4. M.S. El-Genk, H.H. Saber, J. Heat Transf. 120 (1998) 